\title{
HUMAN CAPITAL MANAGEMENT IN THE CONTEXT OF ENSURING ECONOMIC SECURITY OF THE ENTERPRISE
}

\author{
Zinaida Zhyvko' ${ }^{1}$ Iryna Gorban², Nadiia Marushko³, Maryna Korzh ${ }^{4}$
}

\begin{abstract}
${ }^{I}$ Prof. Dr. Faculty of Management and Economic Security, Lviv State University of Internal Affairs, Gorodotska str.29, 79007,Lviv, Ukraine.Phone Number+380964441055,E-mail: zzhyvko@yahoo.com

${ }^{2}$ Assoc. Prof. Faculty of Management and Economic Security, Lviv State University of Internal Affairs, Gorodotska str. 29, 79007, Lviv, Ukraine. Phone Number+380678571046, E-mail: gorban133@yahoo.com

${ }^{3}$ Assoc. Prof. Faculty of Management and Economic Security, Lviv State University of Internal Affairs, Gorodotska str. 29, 79007, Lviv, Ukraine. Phone Number+380967786398,E-mail: n marushko@i.ua

${ }^{4}$ Assoc. Prof. Educational and Scientific Institute of Accounting, Analysis and Audit, University of the State Fiscal Service of Ukraine, Universytetska str. 31, 08201, Irpin, Ukraine. Phone Number +380950731666, Email: __korzh@i.ua
\end{abstract}

\section{Received 30122019 12, Accepted 2905292020}

In today's conditions, when a pandemic significantly affects the economy and its security, it is very important to ensure protection both at the state level and at the enterprise level. The most vulnerable are people who, as employees of the enterprise, significantly affect the development of the enterprise. The main goal of the article is to study the process of managing the formation of human capital as the basis of the national economy and ensuring the economic security of the enterprise. The basic components of human capital are determined based on the analysis. It is established that the basic component is knowledge that affects others and in modern conditions of development of the national economy and determines the process of development of human capital. The results of the study allowed us to develop a model for the formation of human capital and to form a mechanism for ensuring the economic security of the enterprise through management of the formation of human capital. Thanks to the methods of analysis and synthesis, a model of human capital management in conditions of ensuring economic security was formed. mechanism.

Keywords: economic security, human capital, human capital management, national economic, JEL Classifications: J24, J28, J29, M21, O15, E24, H52.

\section{Introduction}

A characteristic feature of the modern era is the emergence of innovative means of information exchange and the development the network of information technologies. The mass character and prevalence of these processes allows us to characterize them as a kind of "information revolution", which marks a new era, which: changes the ways of formation, organization and dissemination of information; creates new forms of relationships, including relationships of social actors; affects all spheres of society (politics, economy, culture, etc.); provides a wide range of information base; opens up the possibility of active, almost unlimited search for the necessary information. That is, the modern social environment of a person is more than once formed under the influence of modern information technologies, and access to information becomes a criterion of a highly developed society.

Copyright (C) 2020. Published by Vytautas Magnus University. This is an open access article distributed under the terms of the Creative Commons Attribution Non-Commercial 4.0 (CC BY-NC 4.0) license, which permits unrestricted use, distribution, and reproduction in any medium provided the original author and source are credited. The material cannot be used for commercial purposes. 


\section{Zinaida Zhyvko, Iryna Gorban, Nadiia Marushko, Maryna Korzh \\ Human Capital Management in the Context of Ensuring Economic Security of the Enterprise}

The most significant resource of the modern economy, which is being formed in the leading countries of economic development, including the EU, and which is defined as the "cost of knowledge", is human capital, which, based on the systematic generation of new knowledge, stimulates and ensures the development of the latest technologies conducive to the development of social, economic, humanitarian, cultural and other spheres of public life. At the present stage of development - the active development of the knowledge economy - human capital fulfils the function of the driving force of social progress, and therefore requires special attention at all levels of government, including and with the aim of ensuring economic security, where a person fulfilling the role of both the subject and the object of security.

The development of a modern economy requires the state and the enterprise to use their resources more efficiently. As experience shows, both foreign and domestic, the main resource is human capital. The growing role of human capital in the formation of the "knowledge economy" has led to the importance of evaluating the human capital of an enterprise when choosing an innovative strategy. Among the main reasons for the lack of innovative activity of enterprises, experts highlight the lack of qualified, innovatively active personnel, as well as the low level of its innovative culture. The processes of globalization and integration into the world economic system have led to the emergence of new approaches in the implementation of the management process and the beginning of the transition to knowledge of a basic economy. Of relevance is typing this issue in the context of enterprise security.

The purpose of the article is to study the process of managing the formation of human capital as the basis of the national economy and ensuring the economic security of the enterprise.

The object of study is the enterprises of Eastern Europe.

The subject of the study is human capital, the economic security system of the enterprise.

To determine and justify our research, we applied the following methods: induction and deduction, comparison and systematization - in the study of the essential characteristics of human capital and its main components; synthesis and analysis - to justify the need for the formation of a model of human capital management in conditions of ensuring economic security; morphological analysis - to characterize the main components of the human capital management system; graphic for a visual representation of theoretical and methodological material; abstract-logical - for theoretical generalizations and conclusions of the study.

Basically, for our study, we used methods of analysis and systematization, which allowed us to carry out a theoretical analysis and form a general idea of the essence of human capital management. Thanks to the expert method, we analyzed the opinions of experts on pre-existing problems of ensuring economic security and identified the main problems in this area, concerning the personnel management system and, using the graphical method, reflect the mechanism of ensuring economic security in the context of human capital management.

\section{Literature review}

Significant contribution to the development of research on the problem of human capital, carried out by Pelinescu (2015). She investigated the impact of human capital on economic growth.

Bundell and others (1999) also analyzed human capital for economic growth. Their research results showed that the growth rate of production depends on the rate of accumulation of human capital and innovations, the source of which is the stock of human capital, the level of education that affect labor productivity.

Dubra (2019) analyzed the importance of human capital effect on enterprise competitive performance. Her research reveals the definitions of the concept of human capital, and also emphasizes the importance of the influence of human capital on the competitiveness of a company. 
Research into the problems of strategic management of the personnel has gained a new perspective thanks to the analysis conducted by Stoyanova, Koev, Stoyanov, Zhyvko and Laptiev (2019).

The scientific contribution to the development of human capital management at the enterprise was made by Kurcharcikova and Miciak (2018). They designed two approaches for better implementation of human capital management leading to the increase of efficiency, performance and sustainability of enterprises.

In the context of the strategic perspective for the enterprise, human capital management was considered by Yan Yue (2014). He investigates states the connotation of human resource management, defines the concept of strategic human resource management, then analyzes the key functions of human resource management in enterprise strategic development and finally deeply studies human resource management strategies under enterprise strategic perspective.

Pravdiuk, Pokynchereda and Pravdiuk (2019) provide a theoretical substantiation and systematization of existing methods for assessing human capital, to identify the advantages and disadvantages of their practical application in the enterprise activity, and to develop recommendations aimed at improving the human capital assessment methodology in order to further reflect information on the cost of human capital assets in accounting and reporting of enterprises.

Paying tribute to the scientific contribution of leading economists, it should be noted that the problem of managing the formation of human capital as a basis for ensuring the development of the national economy and the development of the economic security of the enterprise is still relevant.

\section{Research model and Data}

The modern interpretation of the concept of "human capital" is rather ambiguous, which can be illustrated by differences in its interpretation among the most famous researchers in this field. Fisher, Dornbusch, Shmalenzi (1993) consider human capital primarily as innate abilities and talent of a person, and only then as its achievements as a result of education and qualification. In turn, Denison (1971), Kendrick (1878), Schultz (1968) considered as the capital of each person only his education. A partial combination of both points of view can be found in the approach that was formed by Dolan and Lindsay (1994), according to which human capital is defined as the capital of mental abilities acquired as a result of "formal training, education or on the basis of practical experience".

If for the three approaches described above the main one is the process of human capital growth, for Kurgan (1996) it is the source, so in accordance with its interpretation, human capital is the value of past investments in people's skills, and not the value of people in themselves. Becker (1983) adheres to a similar opinion, since he believes that human capital is everyone's available stock of knowledge, skills, motivation. Investments in it can be education, the accumulation of professional experience, health protection, geographical mobility, information search. These investments improve skills, knowledge or health and therefore contribute to an increase in cash or in-kind income.

A comprehensive approach to the interpretation of human capital, which unites the above described, is the approach of refusals Dyatlov (1996), according to which the term under study is understood:

- accumulated stock of skills, knowledge, abilities.

- a stock of skills, knowledge, and abilities that is appropriately used by a person in an area of social reproduction and contributes to the growth of labour productivity and production.

- the use of this stock in the form of highly productive activities naturally leads to an increase in earnings (employee income).

- an increase in income stimulates interests a person through investments that may relate to health, education, etc., increase, accumulate a new supply of skills, knowledge and motivation, in order to use it again in the future. 
Summarizing the results of a theoretical study and based on the priorities and tasks of human capital in the process of developing the national economy on the principles of a knowledge economy, in our opinion it should be characterized by the following main parameters, which do not contradict, but only generalize all the above points of view (Figure 1).

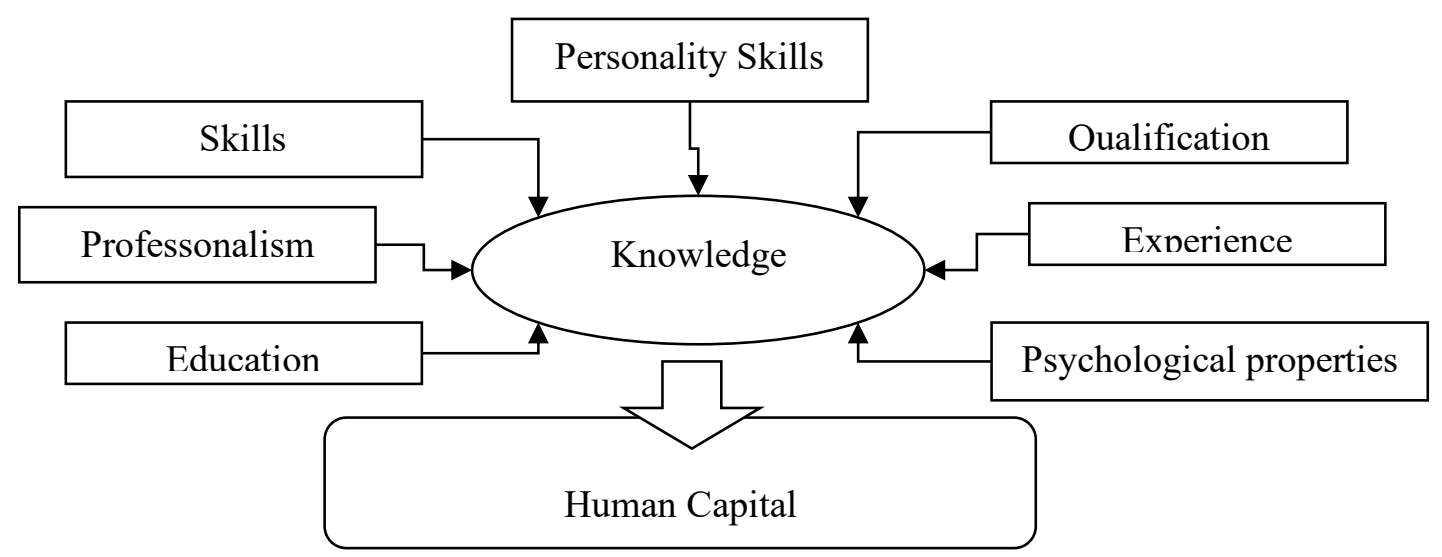

Figure 1. Defining Basic Components of Human Capital

In accordance with the formed interpretation, the key component is knowledge that affects others and in modern conditions of development of the national economy and determines the process of development of human capital. At the same time, the process of knowledge formation itself, in accordance with the principles of the functioning of the knowledge economy, is associated with the availability and possibility of obtaining information, which means that there is a need for a more detailed consideration of these key concepts.

\section{Results and Discussions}

In accordance with the epistemological foundations, any person from the moment of his birth, seeks to know the world around him, for his development and for the purpose of protection there is survival. The source of this knowledge is the information contained in the surrounding world. In the process of the development of mankind, significant changes have occurred regarding the person's ability to obtain information, if at the dawn of the emergence of society it was only the sensory organs of each individual person (vision, touch, etc.), and also, to a certain extent, communication with oneself like that, then in the future, with the birth of writing, a printed book began to serve this. Modern advances in electronics and communications have expanded the ability to quickly obtain any information, but they also created the problem of its excess: with rapid dissemination, it is not structured and not always objective.

The modern realities of the development of society put knowledge at the forefront as the most important resource and the possibility of the continued existence of mankind in conditions of limited natural resources. The process of obtaining knowledge from the entire body of information directly includes its receipt through the mass media, which, in turn, differ significantly in terms of the presentation of data, the size and characteristics of the audience, purpose, etc. The above-mentioned allows us to state that in the conditions of development of the national economy based on the knowledge economy, the development of human capital is most dependent on the existence and possibility of using certain channels of information flow, art. Become the basis for generating new knowledge (Figure 2).

The concept of "mass communication medium" defines not only technical means, but also associated social institutions that perform the functions of disseminating, accumulating and storing 
information. These include libraries. The library sphere as a basic element of informatization of society is currently a fundamental part of documentary and informational, namely, reader communications, has a significant documentary resource, built on the powerful intellectual potential embedded in its funds. The modern system of reader communications has three stable forms: handwritten, printing, and machine-readable. Along with the traditional book, texts are microfilmed and recorded on electronic media: flash drives, floppy disks, laser CD-ROM discs. The substantial progress of scientific and technological progress has radically transformed space and time, the fundamental dimensions of human life. Thanks to its technical and social features, Internet technologies today provide virtually unimpeded access to world information resources. The essence of mass communication is the expediently organized systematic dissemination of specially prepared information among dispersed audiences using technical means. Such technical means that mediate communication between the communicator and its audience are printing, radio, television, cinema, and the Internet.

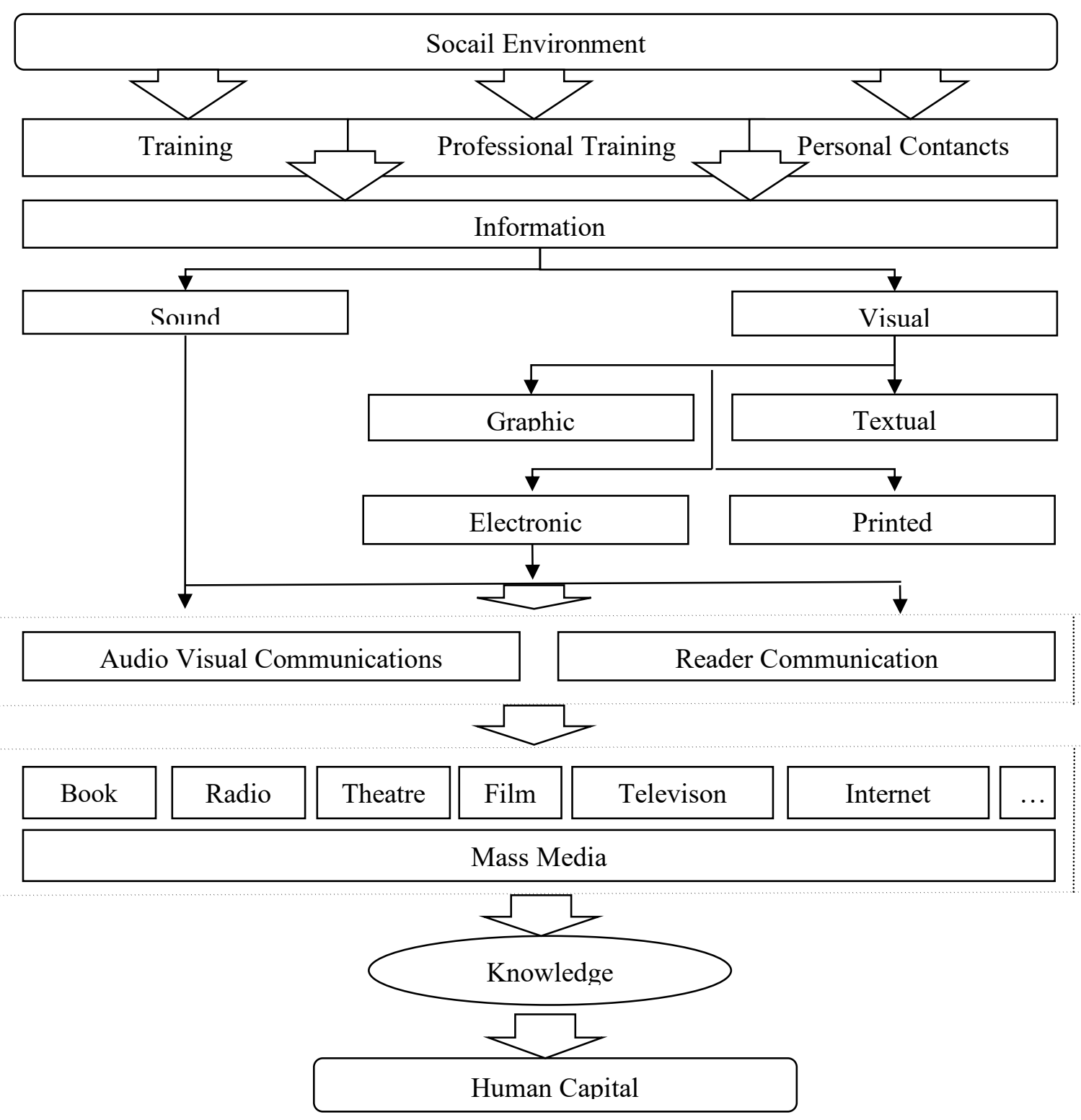

Figure 2. Human Capital Formation Model 
Mass media differ in the time required to receive information (receipt and delivery) and the size of the audience. The press, for example, requires the consumer, above all, free time, but the timing of the reading is not fixed rigidly throughout the day. Appeal to the radio, and to a certain extent to television, does not exclude other parallel activities: for example, you can do homework and listen to text and music. On the other hand, a book should be distinguished, read with any degree of regularity - at a convenient time, and mass media that operate on a clear schedule (in many cases - at a specific time, which is defined as the beginning or end of a day or week, that is, how would set a constant framework for everyday activities). Appeal to the media of communication is a constant and regular type of activity, characterized by a given social rhythm, while reading books is a more selective process, individualized.

The conducted analytical study made it possible to determine key characteristics and differences between individual mass media, their degree of distribution and impact on the formation of human capital.

Mass communication, by the definition of scientists (Ryumshina, 2004), is the process of disseminating information (knowledge, spiritual values, moral and legal norms, etc.) using technical means (printing, radio, cinema, television, computer networks) to large, dispersed audiences. Together with interpersonal and classroom communication, it is one of the most common forms of human communication and information in modern society.

Firstly, the significant socio-psychological difference between printed texts (book, press, Internet) from different types of sound, speech communication is in the maximum individualization of perception, which has a slightly different character than, say, in the cinema. The text is perceived by the eyes and silently. Reading does not absorb other people present in communication, like speaking, does not create obstacles and does not distract them. The reader is detached from the environment, completely immersed in a specific world, reflected in the content of the text. Thus, the printed text develops the individuality of the reader, balancing the integrating influence of audiovisual media and thereby contributing to the harmonious and comprehensive development of the individual, that is, human capital.

Secondly, the perception of TV shows is considered traditional, in this sense, a "natural" act similar in character with everyday personal communication (perception of the text of the presenter) or with the observation of life situations (movies). Every modern person has been involved in such activities since childhood. Similar in nature is the perception of radio broadcasts. So, the results of psychological research indicate that the message is better perceived if they transmit it on television; the next place is broadcast, then a lecture, and the lowest indicators of understanding and assimilation are given by printed text.

Thirdly, the printed text is organized much more complicated: it is relatively more generalized, abstract, rational. The ability to perceive it provides, in contrast to the "naturalness" of entering the world of television or radio, a special education (usually formal). Therefore, if the entire population turns to television and radio, then print information (especially books) is used primarily by people who have received school education (usually at least seven to eight classes).

Fourth, reading develops memory, trains the brain, makes understanding of logical connections, gives the reader freedom of imagination, allowing him to imagine the heroes of the book and events in his own way, that is, that is, it develops human capital. Television offers only to consume ready-made images and schemes. Reading is an active process, watching television is passive. This is best seen in children. Thus, studies conducted in the 80s showed that two-thirds of West German children constantly watched television, with all the literature giving preference to comics. Unlike the "reading" children, they languished and did not know what to do with themselves, if the TV was turned off, they lacked imagination. Instead of giving food to the mind and imagination, they simply killed time.

Fifth, in the press (newspapers, magazines, etc.) Compared with the entertainment and emotionality of television, the reader sees mainly analyticity, which allows a deep and versatile 
coverage of the most important social problems. Therefore, in newspapers, readers primarily seek information about political events.

Sixth, printed sources, turning first to the reader's mind and then to the senses, allow him to more consciously, actively, purposefully, systematically and creatively assimilate cultural values and understand social norms. Printed materials are also irreplaceable in training, education and upbringing, wherever independent creative work is necessary for assimilation, accumulation of knowledge, skills, abilities, for cognition of various problems, aspects of reality. Particularly important is the role of the printed word in the performance of cumulative functions inherent in the QMS, including the accumulation, storage, ordering and systematization of spiritual values developed by mankind throughout its history. Printed texts are the simplest, most playable, and effective form of people's family memory. Due to their structural specificity, they remain the best way to capture cultural information.

Seventhly, as you know, printed materials and audio-visual media have various capabilities in fulfilling the functions of emotional and aesthetic contact, and this also significantly affects the choice of mass media. Thus, the conducted studies show that for the readers, the design of the print edition is important, which is expressed through the harmony of illustration and type design, the integrity of its perception, the expressiveness of the design of its external and internal elements, the original design, that is, its aesthetic appearance. And if in printing all this can be varied indefinitely, then other QMSs do not possess such variability.

Eighth, the individuality in the character of the audience of books and other media of communication is clearly illustrated by the following fact. If there are a number of television programs that are watched by three quarters or more of the audience - concert programs, news releases, etc. - among books (or even genres, themes, series), researchers usually do not find those that they would read (or read regularly) at least half of the audience (except for works included in school curricula, thereby familiar to most readers).

Ninth, according to studies conducted in Poland at the end of the 20th century, $70 \%$ of Poles believed that television adaptations could partially or completely replace the act of reading. In addition, $60 \%$ of Poles chose to watch a film or performance based on a literary work rather than read it. Only $7 \%$ of respondents expressed a desire to first read the book, and then see its adaptation. That is, a read book makes the reader rather watch a television production than watch it while reading a book. For the active part of the public, a film adaptation, as a rule, acts as an exciting motive for referring (often repeatedly) to the literary source. People are not read systematically and rarely; watching such a film will not stimulate access to the work: the film adaptation completely replaces the original.

Tenth, already in the late 70s - early. 80s XX centuries. Despite the influence of the city, written culture, especially books as a specific component of it, was not assigned an important place in the rural environment (Stelmakh, 1982): in small cities of the USSR, 20\% of respondents read books every day, while $47 \%$ of respondents watched TV daily ; in rural areas this difference was even greater: $75 \%$ of respondents watched TV daily, and they also read books $-25 \%$. Surveys were also conducted among different generations of migrants among industrial workers: on the day before the survey almost $41 \%$ of those born in the city and only $24 \%$ of those born in the countryside read. With a sharp transition from the traditional rural lifestyle, television assumes the function of translating social norms and behaviours. Therefore, a certain part of the population, less organically mastered the skills of working with generalized and abstract printed information, in many cases easily changes the communication channel, moving to more "light", "natural", "familiar" forms radio, television, cinema.

Eleventh, manual workers, in comparison with mental workers, generally watch more television than read. Representatives of groups that have passed or are passing through institutions of formal socialization (school or special educational institutions) intensively read in the village and are focused on urban culture. The value of periodicals (newspapers and magazines) in rural areas is 
higher than books. The number of people who watch TV every day in rural areas is 1.5 times more than in small cities, although the population with televisions is approximately the same. With the advent of television in the village, villagers became less likely to turn to books, especially to works of fiction. The weakening of the reading intensity affected primarily population groups, they read very little, which is characterized by a relatively low level of educational and cultural activity.

Twelfth, combining not only educational and cognitive, but also worldview, aesthetic, moral and spiritual potential, the book is a significant factor in the formation of a human personality, his national consciousness, as well as one of the leading media of communication. The book, periodicals and web page, that is, printed text products, are by far the most traditional means of obtaining information, self-education and leisure activities and contribute to the growth of human capital. A generalization of the study was Figure 3, characterizing the differences between audio-visual and reader communications.

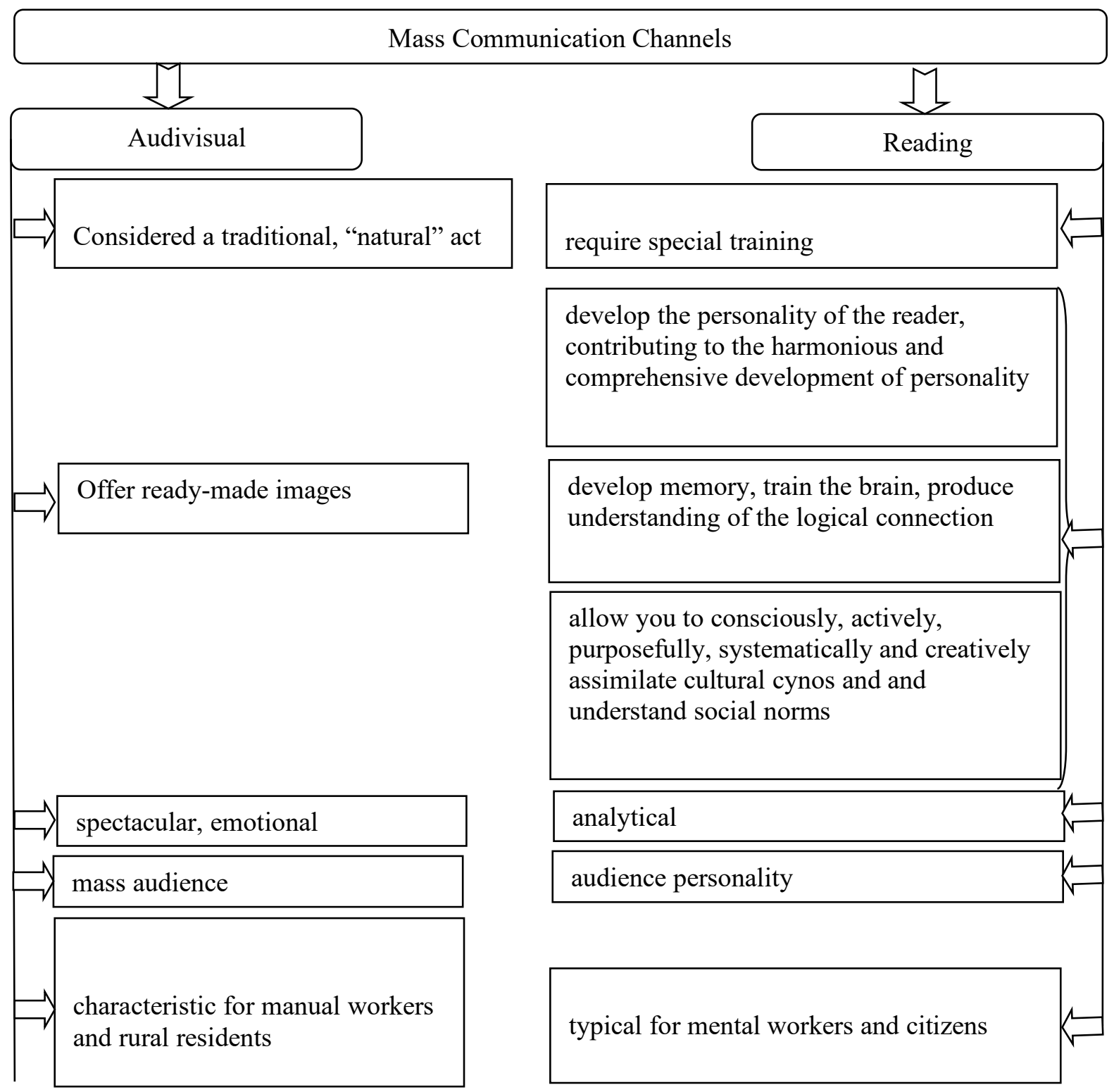

Figure 3. Comparative characteristics of mass communication channels

The characteristics of the media of communication have been characterized that allow us to state that each channel is separate and all of them together are focused on the transfer of knowledge 
that is different in content (meaning the functional specificity of these communication channels). In text form, information is contained in its most complete form, while other media in their nature can only give a signal and arouse interest.

Mass media carry relevant generally important information, and the information contained in textual form is more abstract from a specific moment, is often quite distant in time from the act of perception and is not necessarily important for everyone. Reading presupposes the fundamental possibility of different interpretations of certain classical or, conversely, controversial patterns for mass media - this is an exceptional case. In addition, the text version may contain final specialized knowledge necessary for scientific work, study, individual self-education, and spiritual growth of a person. Therefore, the text version of the transmission of information by the nature of its action differentiates the audience, highlighting those who are interested and interested in knowledge of what exactly is in this text, and often, say, in classical or "complex" literature, appeals to the face of the reader, to his own spiritual experience and independent value judgment.

A significant increase in the amount of information and the methods of their transmission occurred at the turn of the XX-XXI centuries. The main directions of change are that, on the one hand, public interest in traditional forms (reading books, listening to the radio, visiting theatre performances and concerts) is weakening, and on the other, the importance of audio-visuals is growing. These changes have intensified over the years and have been clearly manifested in recent decades, directly affecting the development of national economies. If economically developed countries, including the EU, clearly show trends in improving people's access to information resources, in particular the Internet, which can also be attributed to reading channels of mass communication, provides a gradual increase in human capital, and therefore increases the rate of economic growth, for others, this is an important problem that needs to be addressed. It can be argued that the growth of human capital is a key condition for the economic development of each country, as long as traditional natural resources are exhausted or lose their significance.

Another aspect of the problems identified is that human capital plays a key role in the process of ensuring the economic security of each enterprise, because it is directly related to the main components of the integrated system of economic security, in particular the facilities and entities that the enterprise's personnel act, and then ensuring economic security is most dependent on the development of human capital at the macro level, that is, as was proved above, the possibility of obtaining information and generation of new knowledge (Figure 4).

In a graphical form (Figure 4), those elements of the integrated system of economic security of the enterprise are clearly distinguished whose level of knowledge directly affects the process of ensuring the economic security of everyone who is gifted, in particular:

- personnel of the enterprise as an object of security;

- enterprise personnel, which is conditionally divided into three categories with respect to the functions performed to ensure safety (specialized, specialized and non-specialized) as a security entity.

We also allocated law enforcement officers, security companies, etc. as external subjects of security, because the level of economic security at a given enterprise also largely depends on the level of their knowledge and other elements of human capital.

Achieving the main goal of an integrated system of economic security for food production in the conditions of the development of the national economy is possible due to the growth of human capital, that is, investing in training, self-education, advanced training, self-improvement, obtaining new information, generating new knowledge about each individual employee of the enterprise. 

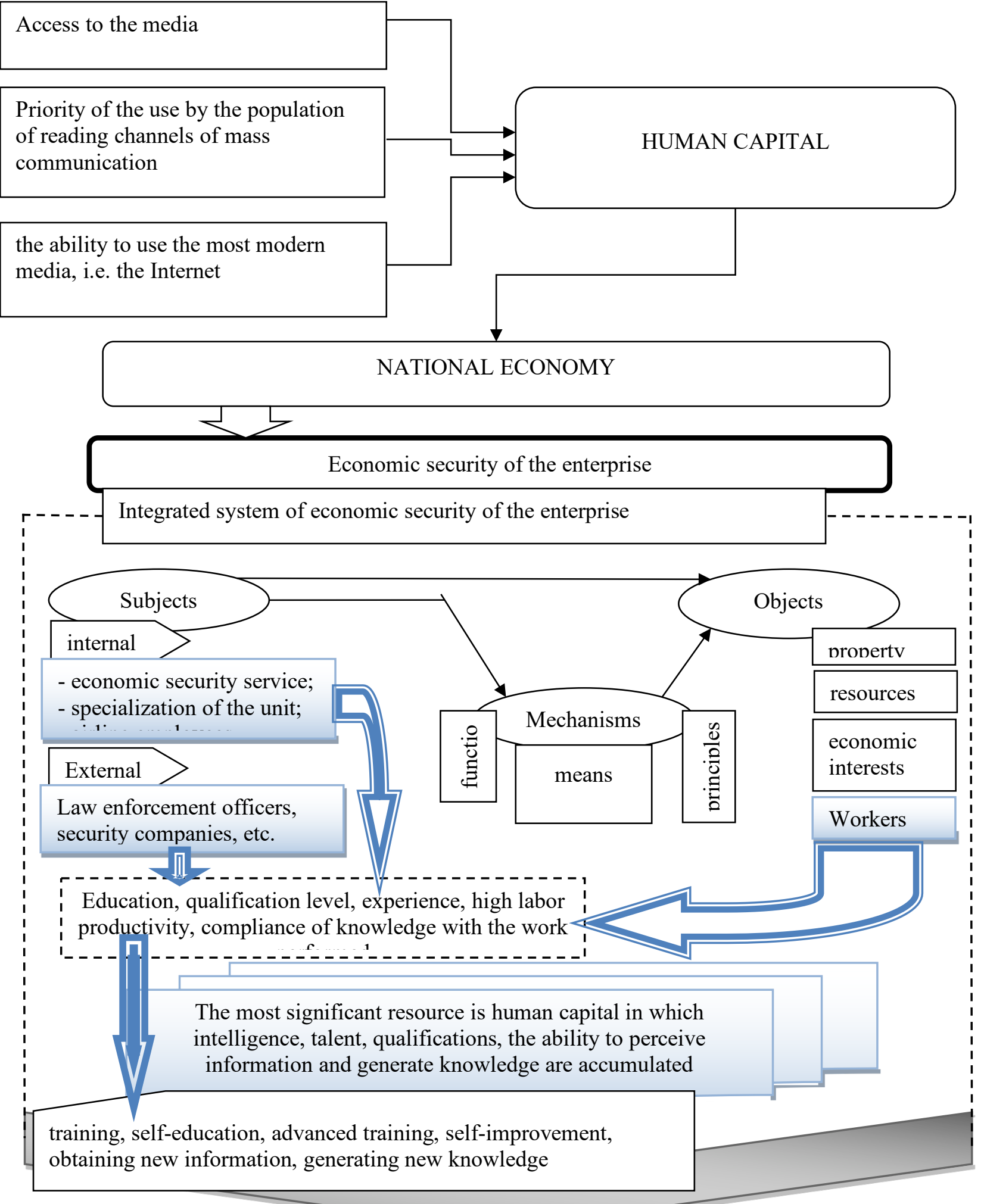

Effective use of available resources and market opportunities, ensuring sustainability and realization of interests, protection against external and internal threats, interest protection, internal insurance and internal threat

Figure 4. The mechanism for ensuring the economic security of enterprises by managing the formation of human capital 


\section{Conclusions}

Further dominance of countries with developed economies, including the EU, is directly related to human capital, the formation of which largely depends on the level of knowledge, the generation of which is based on information received through various media channels, the value of which has significantly changed under the influence of scientific development-technical progress, but which differ in the level of impact on the individual and the ability to create new knowledge based on their use.

The countries of the former Soviet Union, in particular Ukraine, seeking to join and take their rightful place in the world community, became open to network information technologies; today, thanks to technical and social features, they transform the modern perception of the world of citizens, change the logic of relations, etc. In addition, ownership skills and the active use of the latest technologies for receiving and transmitting information significantly affects the process of formation of personal characteristics of each person, and therefore the process of formation of human capital.

The increase in the level of human capital as a prerequisite for ensuring the level of security necessary for the development of the enterprise in the conditions of the development of the national economy is possible through the active use of reader communications, which provide the necessary information and generate new knowledge.

It can be argued that priority is given to giving attention at the level of each individual country to three key areas that, in our opinion, deserve special attention:

firstly, ensuring access of the population to the media of communication, including through the growth of its purchasing power;

secondly, it is obtaining information and converting it into knowledge using the reader channels of mass communication;

thirdly, the ability to use the most modern media, that is, the Internet.

The solution of this problem at the country level contributes to the achievement of economic interests in the national economy as a whole and will contribute to the achievement of the necessary level of economic security of each individual enterprise. The effectiveness of managing the economic security of an enterprise whose personnel in the integrated system of economic security simultaneously plays the role of both the object and the subject of economic security is most dependent on human capital, the growth of which can be ensured by the active receipt of information by readers through readers' communications (printed book and the Internet) that contribute most to the development of memory, train the brain, produce an understanding of the logical connection, the meaning of power impair the intellectual potential of man.

\section{References}

Pelinescu E. (2015) The Impact of Human Capital on Economic Growth // Procedia Economics and Finance. Volume 22, pp. 184-190. DOI: https://doi.org/10.1016/S2212-5671(15)00258-0

Bundell R., Dearden Lorraine, Meghir C., Barbara Sianesi (1999) Human Capital Investment: The Returns from Education and Training to the Individual, the Firm and the Economy // Fiscal Studies, Vol. 20, no. 1 , pp. 1-23.

Dubra I. (2019) Human Capital Impact on the Enterprise Competitiveness. Conference: Young Scientist International Confrenence. pp. 55-59.

Stoyanova T., Koev S., Stoyanov Ph., Zhyvko Z., Laptiev V. (2019) Strategic Management of the Personnel Development of Industry Companies // Academy of Strategic Management Journal. Vol. 18, No 3.

Kurcharcikova A., Miciak M. (2018) Human Capital Management in Transport Enterprises with the Acceptance Sustainable Development in the Slovak Republic // Sustainability, pp.1-18.

Yan Yue (2014) Human Resource Management under Enterprise Strategic Perspective. International Conference on Education, Management and Computing Technology (ICEMCT 2014). pp.185-189. 
Pravdiuk N., Pokynchereda V., Pravdiuk M. (2019) The Human Capital of an Enterprise: Theory and Assessment Methodology // Baltic Journal of Economic Studies. Vol.5, No.2. pp. 176-184. DOI: https://doi.org/10.30525/2256-0742/2019-5-2-176-183

Denison E. (1971) Investigation of differences in economic growth rates. M., 645 p.

Kendrick J. (1878) The total capital of the United States and its formation. M: Progress, $275 \mathrm{p}$.

Schultz T. (1968) Resources for higher education: an economist's view // The Journal of Political Economy Vol. 76. No. 3.

Dolan, E., Lindsay E. (1994) Microeconomics. SPb., 256 p.

Kurgan S. (1996) Fundamentals of the theory of human capital. Irkutsk: IHEA Publishing House, 334

p.

Becker G. (1983) Human capital. The University of Chicago Press, Chicago and London.

Dyatlov S. (1996) Theory of human capital / S. A. Dyatlov. SPb. 325 p.

Ryumshina L. (2004) Manipulative techniques in advertising: textbook. allowance. M.: Rostov-onDon, March, 240 p.

Stelmakh V. (1982) Interaction of the book with the media. Paris: UNESCO, 1982. 56 p. 